\title{
THE IMPORTANCE OF USE OF TECHNOLOGY BY ELDERLY IN TERMS OF INTERGENERATIONAL COMMUNICATION AND SOCIAL IMPACT
}

Fahri ÖZSUNGUR ${ }^{1}$

\begin{abstract}
This article focuses on the use of technology in terms of intergenerational communication and social impact. The theoretical approaches affecting the use of technology in intergenerational communication have been examined and emphasized on the importance of social classes and groups' intergenerational communication. The effects of the use of technology on the elderly have been assessed within the context of social classes, groups, and generations. In addition to the rapidly evolving technology, the issue of ageism, which interferes with intergenerational communication, is also mentioned in this review article. In this article, the emphasis was put on the importance of formal and informal education on the use of technology in the strengthening of intergenerational communication, with the result that technology facilitates the daily work of the elderly and strengthens their social communication, thus contributing significantly to intergenerational communication. The Global Class Theory, which underlie human, emphasized that the classification of individuals should be based on human values and that the elderly individual may exist in all areas of these classes. Increasing the qualitative and quantitative studies to be done in this field due to the importance of technology acceptance and use and intergenerational communication on seniors will contribute to the literature. For future studies, qualitative and quantitative researches on the use of technology and the acceptance behaviors of the elderly are suggested in terms of intergenerational communication and social impact.
\end{abstract} impact

Key Words: Intergenerational relations, use of technology, ageism, gerontechnology, social

Dr. Fahri Özsungur, Adana Alparslan Türkeş Bilim ve Teknoloji Üniversitesi, İşletme Fakültesi, Uluslararası Ticaret ve Finans, ticaretsicili@gmail.com:, ORCID: 0000-0001-6567-766X

Özsungur, F. (2020). The Importance Of Use Of Technology By Elderly In Terms Of Intergenerational Communication And Social Impact. Sosyal Politika Çalışmaları Dergisi, 20(47), 411-440. DOI: 10.21560/ spcd.vi.556988 


\section{KUŞAKLARARASI İLETİ̧̧IM VE SOSYAL ETKİ AÇISINDAN YAŞLILARIN TEKNOLOJI KULLANIMLARININ ÖNEMI}

\section{Öz}

$\mathrm{Bu}$ makalede kuşaklararası iletişim ve sosyal etki açısından teknoloji kullanımının önemi üzerinde durulmuştur. Kuşaklararası iletişimde teknoloji kullanımını etkileyen teorik yaklaşımlar incelenmiş, sosyal sınıflar ve grupların kuşaklararası iletişimdeki önemi vurgulanmıştır. Teknoloji kullanımının yaşlılar üzerindeki etkileri sosyal sınıflar, gruplar ve kuşaklararası iletişim kapsamında değerlendirilmiştir. Makalede hızla gelişen teknoloji ile birlikte kuşaklararası iletişime engel oluşturan yaş ayrımcılığ 1 konusuna da yer verilmiştir. Tüm bu değerlendirmeler ışığında teknolojinin yaşlı bireylerin günlük işlerini kolaylaştırdığg ve sosyal iletişimlerini güçlendirdiği, böylece kuşaklararası iletişime önemli düzeyde katkı sağladığı sonuçlarına varılarak, kuşaklararası iletişimin güçlendirilmesinde teknoloji kullanımına ilişkin örgün ve yaygın eğitimin önemi vurgulanmıştır. Temelinde insan olan Global Sınıflar Teorisi ile bireylerin sinıflandırmasının insani değerler üzerine yapılması gerektiği, yaşlı bireyin de bu sınıfların her alanında var olabileceği vurgulanmıştır. Gelecek çalışmalar için kuşaklararası iletişim ve sosyal etki açısından yaşlı bireylerin teknoloji kabul ve kullanım davranışlarına yönelik nitel ve nicel araştırmaların yapılması önerilmektedir.

Anahtar Kelimeler: Kuşaklararası ilişkiler, teknoloji kullanımı, yaş ayrımcılı̆̆ı, geronteknoloji, sosyal etki 


\section{Introduction}

Along with the development of technology, the communication network has expanded rapidly, electronic devices have been made compatible with one another, and the possibility of communicating with the internet network in computers, smartphones, televisions, cars, and public transport has been brought to humanity (Berg, Kemperman \& Kleijn, 2016). This rapid development and change of technology has shown its effects on individuals' lives. Thanks to the technology, daily activities can be carried out easily over the internet, meetings can be held online, shopping can be done without leaving the house via virtual markets, and banking transactions can be realized via internet banking. Technology is also important in terms of relations with social entities. Social classes, which are important structures of society, have become more active in interacting with groups with developing technology. Elderly individuals are trying to adapt to technological devices with the development of technology, and the young generation has begun to take the example of active communication technology (Harwood \& Giles, 2005). The prominence of technological advances in intergenerational communication and interaction also implies the importance of social influences. The influencing of technology use by interaction within social groups and classes ensures that the elderly person takes social class or individuals within the group as an example. Interaction within social classes and groups is also increasing thanks to the communication network that develops with technology. Especially encouraging elderly people to use technology in intergenerational communication is important in this respect. The increase of intergenerational interaction is an important issue that will enable the elderly person to be successful in psychological and social aging, which will reduce the social isolation situation (Rosengren, 2000). The lack of studies on the importance of using the technology of the elderly in the context of intergenerational communication and social influence in the literature shows the importance of this study.

The aim of this study is to investigate the technology usage of elderly people in the context of intergenerational communication, developing technology and a social class theory based on the human element. The other aim of the study is to make recommendations to practitioners, policymakers and 
academicians with the findings. For this purpose, the research question was determined as follows: How is the use of technology in the elderly affected by social class, technology, and intergenerational communication? What are the recommendations regarding these effects?

\section{Research Metodology}

In this study, a systematic review method was applied. identification, review, analysis, summarization, discussion, and presentation stages required by the systematic review method (Uman et al., 2008). The research question was determined proportionally for the purpose of the study. After determining the framework of the study with the research question, a literature review was performed. The information was coded and theme titles were created (Uman, 2011). After the theme titles were listed, the study was reviewed to create integrity (Petticrew \& Roberts, 2008).

The effects of the use of technology on the elderly have been assessed within the context of social classes, groups, and intergenerational. In addition to the rapidly evolving technology, the issue of ageism, which interferes with intergenerational communication, is also mentioned. In this review article the importance of use of technology by elderly in terms of intergenerational communication and social impact have been assessed within the issues of intergenerational communication, theoretical approaches, intergroup approach, group motion hypothesis, social relations/comparative theory, balance theory, epistemological hypothesis, social impact, normative social impact, informational social impact, informational general view influence, progressive informational social influence, global class theory, reference groups, technological impacts on elderly and ageism. These theories are aimed at explaining the social relationship between the use of technology and intergenerational communication. Intergenerational interaction is an important issue that can positively affect the tendency of older individuals and young people to share information and use technology. The epistemological hypothesis comes to the forefront in the context of the transfer of knowledge through social interaction, global class theory, and reference groups in the context of the roles of the individual in groups and classes. In this study, the 
importance of social support in the context of the use of technology for elderly individuals was tried to be revealed.

\section{Intergenerational Communication}

Communication refers to mutual sharing and sharing of differences (Rosengren, 2000). Sharing happens with message flow. Individuals send messages to their surroundings throughout their lives and receive messages from their surroundings. This message flow has a specific interaction. Communication comes along with interaction. The physical, mental, and mental changes that occur with aging affect the messages that surround it and messages that surround it (Harwood \& Giles, 2005). Intergenerational communication; is an intellectual and cultural, multi-faceted interaction tool and a group of interactions among which the individuals who make up different age groups perform reciprocal physical, cognitive, psychosocial, and experiential sharing (Rosengren, 2000; Harwood \& Giles, 2005). Generational communication becomes stronger with harmony between people and groups (Giles, Coupland \& Coupland, 1991). According to a study, new communication technologies such as internet banking and e-government mobile applications was used effectively in many areas of daily life by elderly people due to intergenerational communication (Becerikli, 2013).

\section{Theoretical Approaches}

There are three basic theories that explain intergenerational interaction: the theory of communication adaptation, the inferential theory, the theory of communication dilemma. The theory of communication adaptation, which explains the interaction between people and groups with social, psychological and linguistic variables, reveals the predictions and explanations of social linguistic behaviors. When groups are divided into age categories, individuals at all age levels are more compatible in terms of communication with individuals at their own level. According to this approach, the adaptation behavior of the speaker depends on the speaker's perceptions, evaluations, the motivation of the speaker, acceptance of the others or being noticed by other social groups 
(Giles, Coupland \& Coupland, 1991). The theory is important in terms of intergenerational communication between individuals and groups.

One of the important theories for intergenerational interaction is the inferential theory that Gumperz (1992) put forward. According to this theory, in the transfer of knowledge between individuals, rhetoric, grammar, language features help to communicate perception and daily communication (Gumperz, 1992). This leads to an inferential process that takes place between communicating the information and communicating it. Many ethnic intergroup and intercultural studies have shown that the inductive process triggers intercultural communication. This process focuses on speech features and clues to handling together with the items around any topic. The inferential theory is examined in three forms, perceptual, speech and action levels. The perceptual level allows the individual to distinguish between topics that are shared in the context of new information conveyed or in which the order of the known items, importance ratings, and prior knowledge are known. The level of speech indicates the intent to communicate. With high or low voice, paced, intermittent, hesitant, the conversation can cause the communicator to misinterpret the message and find positive or negative comments about the communication. The level of activity also referred to as the general level, This expectation depends on the quality and environment of the relationships (Gumperz, Aulakh \& Kaltman, 1982). The theory contributes to the improvement and sustainability of intergenerational communication by emphasizing the importance of culture, language, and perception in the interactions of generations.

The theory of communication dilemma in the elderly, which explains cognitive and communicative processes in intergenerational interaction, suggests that young adults have a negative influence on the intergenerational communication options of the elderly with stereotypes about elderly individuals. This may lead to psychological well-formed declines, low social interaction quality, and a significant decline in physical health. The theory of communication dilemma in the elderly explains the relationship patterns of behavioral relationships between cognitive and communicative processes in intergenerational interactions with the influence of related perception 
(Hummert, 2010). The influence of perception on the relationship between generations of negative and positive behavior patterns forms the basis of the theory of dilemma in communication. The stereotypical anticipation of young adults for the elderly has a negative impact on intergenerational communication options (Ryan et al., 1995).

\section{Intergroup Approach}

The intergroup approach to intergenerational communication is important because each individual has set out from the fact that they include a group. In the use of technological products, the interaction between the groups in which the individual is involved causes a positive or negative perception. This is due to the group influence which exceeds the effect of technology. It is possible to see the effects of groups in communication, especially among young and old groups. It has been determined that the subject which focuses on a study in which elderly individuals are described as arrogant, authoritarian, incompatible with young people is not the subject studied but social relation and perception. In the same study young people described elders as negligent. For this reason, communication is weakened between the two groups (Ryan, et al., 1995). Other researches on communication and perception among young people and elderly show that elderly individuals are seen as less satisfying, problematic, arrogant for their roles and prejudiced for their age (Hummert, 2010).

It also provides for behaviors such as being a social being, trying to maintain life in groups and social formations, and being involved in a group. The individual, who tends to classify himself and other individuals according to their demographic characteristics, is essentially in search of an identity. This creates a clear prejudice for every entity outside the center of the individual (Tajfel \& Turner, 1985). Prejudice against another individual that an individual classifies according to a certain category can also be achieved against the technological products used by this other individual. It is possible to say that the same opposition may apply to product use and technology perceptions when it is thought that the opposition is likely to occur in terms of individuals among the groups (Rabbie, 1982). This adaptation can be achieved through 
intergenerational cooperation studies, activities that increase the interaction between the youth and the elderly. The finalization of these conflicts depends on the compatibility that will occur between the groups. Especially the effect of intergenerational communication on the use of technology is important for group cohesion (Hjälm, 2012). Harmony between groups can help to improve the interactions of older individuals with technology via intergenerational cooperation.

\section{Group Motion Hypothesis}

Theimpacton themembers of the groupinintergenerational communication is important in terms of sanction, consumption, use or termination of the products (Paulus, 1989). Groups control their members with social pressure. The threat of inclusion and exclusion from the group makes the individual obey the group rules. This requires involvement in a specific harmonization process. The continuity of the group and the common objectives can be achieved through the harmonization of the common decisions of the individuals (Festinger, 1950). Deviation in the common sense pushes the individual out of the group, which can also cause problems with inclusion in other groups. Social support; emotional, concrete, helpful, priceless, informative, multidimensional support that the participation of families is important (Wang, Wu \& Liu, 2003). Especially the social support that the elderly need for use of technology and the willing attitude of the young people to participate in the group make the importance of the group motion hypothesis (Egolf, 2001). Technological tools help the individual to realize the social support they need. Interviewing the elderly person who is in search of social support, via the internet or smartphone, affects intergenerational communication. When the involvement of the family is important or when a desire to participate in a group emerges, the technological means of communication strengthen interpersonal communication and interaction. Technological devices such as computer games, cinema, music player electronic devices, television, and DVD allow individuals in different age groups to share (Wang, Wu \& Liu, 2003). 


\section{Reference Groups}

Another factor that influences elderly individuals and consumers in the cognitive process is the reference groups. Reference groups may influence brand choice and may also include brand-based groups. These groups also affect individual or public necessity or unnecessary luxury spending (Lantos, 2011).

As seen in Figure 4, the reference groups are based on the nature of the interaction. However, the distinction in the final group type has shifted to membership or not. Direct reference groups appear to be divided into primary and secondary members who are members. Indirect reference groups can be seen as non-members, but aspirational and non-members but nonaspirational members. In this case; direct reference groups are members, and indirect reference groups are non-members. The literature also distinguishes between membership groups, automatic groups (depending on age group or gender), negative groups (groups that undesirable to be associated), and positive groups (groups to be associated) (Strydom, 2004).

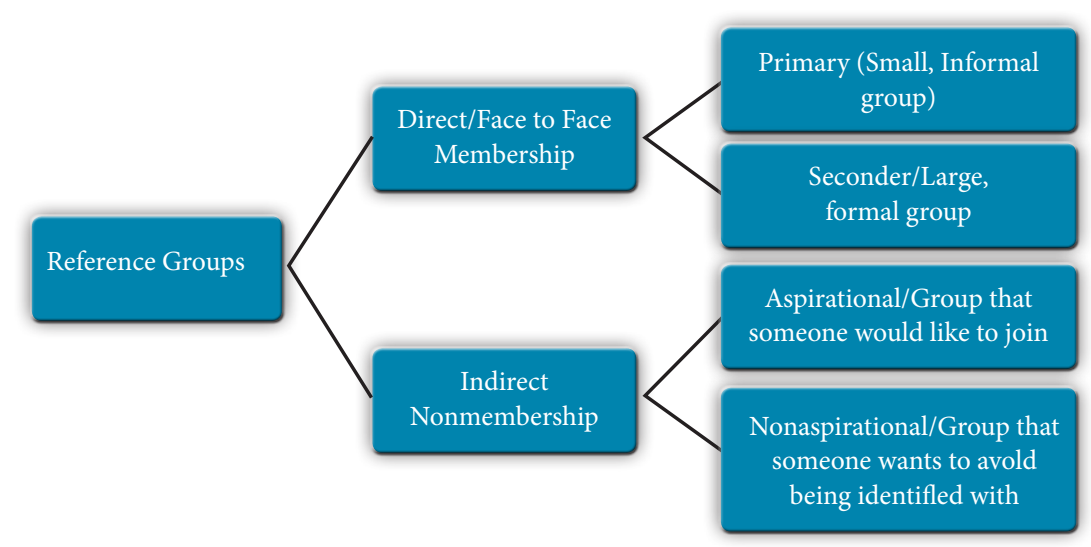

Figure 4. Charles Lamb, Joe Hair ve Carl McDaniel's Reference Groups

Source: Adapted from Lamb, Hair \& McDaniel (2009).

As shown in Figure 5, the interactive groups are divided into forms of advisory and discussion groups. In interactive groups, interaction is possible regardless of the condition of being a member between the groups and the 
individual. Individuals may engage with group members to get an idea of the common opinion of the reference group before making its decision or making a decision (Asch, 1951). The realization of interaction depends on the nature of the interaction of the group. Advisory groups provide advice to individuals about the decisions they make. The advisory takes the form of communicating the group's pre-established general evidence to the individual. This can only affect an individual's personal decisions. Common opinion is established in the advisory group. Discussion groups are groups that are open to individual views. There are predefined general proofs, but not certain. The common sense may vary with the problems and solutions that individuals present and problems they experience. Measuring groups are groups that the individual does not actively consult in decision-making, only to sample or stay away (Schulz, 2015). These groups can contribute to the technology usage and interaction of older individuals. The acceptance and use of technology may vary depending on the group's characteristics. For example, discussion groups are open to the views of individuals, so that the elderly can access the knowledge they need regarding the problems in the interaction of technology.

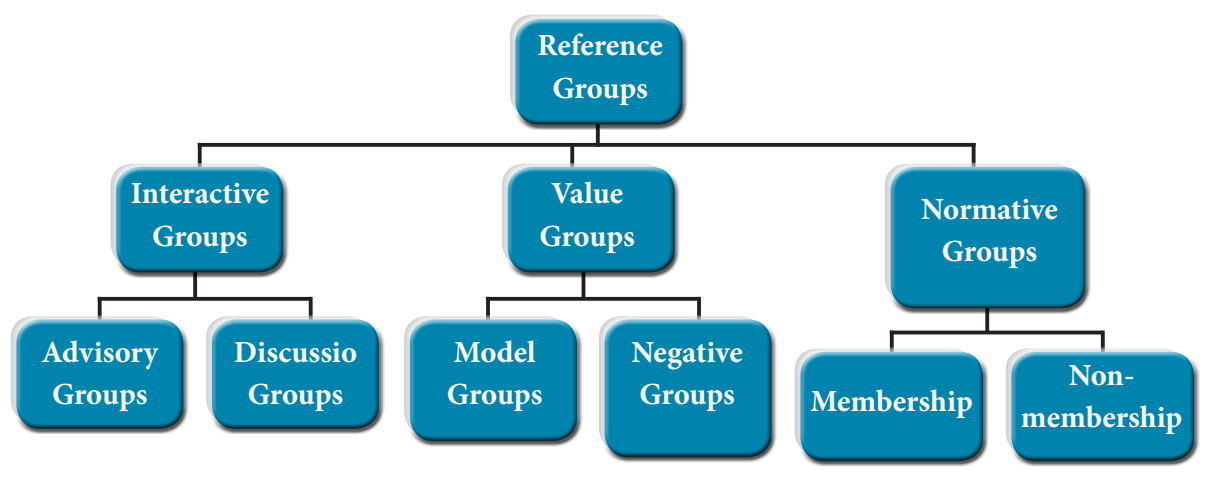

Figure 5. Forms of Reference Groups

Source: Adapted from Lamb, Hair, McDaniel (2009).

Positive groups are groups that affect the degree of commitment of the individual in decision-making. These groups are societally accepted groups, with a consensus on purchasing, whether they are members or not. Individuals take these groups as examples to enter groups, protect statutes in the group, 
or not to leave the group. An example of this is the adoption of an individual model of consumption behaviors of groups of lawyers (Hammerl et al., 2016).

Negative groups are groups that are negative for the decision making that individuals are away from. The negativities of these groups, created by individuals with bad habits, will inevitably affect the decision-making and procurement processes, such as being excluded from society. It is characteristic of the negative group (Hammerl et al., 2016). Consumer negative group may take a negative measure and may conclude the purchasing decision process negatively. The group formed by smokers constitutes the negative group. When the consumer considers this group as lung cancer and the deceased members as a measure, the decision to purchase the cigarette is negative. Consumers can spend their money on other products rather than spend on cigarettes. Another example is that a consumer who wants to stay away from the fast-food group has a negative decision to buy fast food and decides to buy healthier food (Radford, 1989).

Normative groups are non-interaction groups. In these groups, the rules are strict and exact. Individuals can not consult their opinions and share their views on these groups in the procurement decision process. The group describes the predefined rules to the group members and assumes everyone knows these rules. Many behaviors are not approved by group members. The individual group does not have the right to comment on the rules of the group and is threatened to exclude from membership of the group. Directly influences the consumer's purchasing decision process for the regulatory groups that are members. The consumer behaves in accordance with the common sense of the group or folds on the consequences of not acting. Non-membership of normative groups can also influence the decisions of non-group members. Non-member individuals may act in accordance with the common belief of the group to be a member and to be able to demonstrate the group. Sometimes, in the absence of a group member, the decision of non-members can be taken as a basis in the decision-making process to support the decision and clarify the decision (Radford, 1989).

As a result, reference groups can contribute to the strengthening of intergenerational communication of elderly individuals, providing the 
necessary support and information flow in the problems that may be experienced with technology, and sharing experiences.

\section{Social Relations/Comparative Theory}

As a result of being a social entity, individuals follow the behavior and attitudes of individuals outside of them. Essentially, this is the beginning of intergenerational communication. The theory of social relation/comparison moves from this beginning. According to this theory, individuals compare others with themselves. Every individual carries out the behavior he or she sees in other individuals and thinks is appropriate. The importance of being positive or negative in the objective sense of the behavior is important for the perverted behavior to take place. Because heresy gives real damage to the social situation (Paulus, 1989).

Social relations are important in terms of technology acceptance. The elderly person " $\mathrm{S}$ ", who is hesitant to use a new technology "Y" brand product, may be interested in this product as a result of seeing the use of the young person " $\mathrm{B}$ " who is in contact with intergenerational. In terms of technology acceptance, the younger individual tends to accept technology with societal comparability, as the elderly person assists in introducing and using the product with bilateral relations. (Gass \& Seiter, 2014). The pleasure sensation obtained when using technology plays an important role in the development of intergenerational of positive individuals in elderly people. This suggests that elderly people perceive positively by comparison with what young people feel (Chua et al., 2013).

\section{Balance Theory}

In intergenerational communication, balance ensures healthy relations. According to the balance theory proposed by Heider (2012) point to a trio relationship that me, my friends and my enemy, me and my friend, me and my enemy, my friend, and my enemy. This constitutes the basis of the balance theory between the triples (Heider, 2012). Individuals' thoughts about others are important in this sense. These thoughts are the basis for reaching some 
realities about the future. The use of technology may become easier and more appealing to intergenerational communication. The transfer of necessary knowledge about intergenerational communication, the mutual presentation of perceptions to the product, the observation of deficiencies in information, the errors of the product and the ergonomic situations are important in terms of reaching the reality of the future (Kruglanski \& Stroebe, 2011). Since equilibrium theory is based on the idea of achieving the necessary balance in individuals' relations, the balance established in the relations will bring social support and thus, individuals can obtain the necessary support in matters that they are lacking such as communication and technology.

\section{Epistemological Hypothesis}

Harmonization of personal and social information in the relations between the group and group members comes into the epistemological hypothesis based on information theory (Gass \& Seiter, 2014). Individual information acquisition takes place both individually and socially. Personal information is acquired through experience, observation, social information, and communication. If both the individual and the social information about the same subject are acquired, these two pieces of information may conflict. The same conflict can also take place between group decisions and individual information or social information decisions (Campbell, 2015). This harmonization problem between the group and the individual can be seen as "joint harmony and personal agreement", "joint harmony and personal disagreement", "joint nonconformity and personal agreement", "joint nonconformity and personal disagreement" (Levine, 2013). These types of incompatibilities that can be realized between the group and the individual in terms of the use of technology will affect intergenerational communication. It refers to the cohesion and personal disagreement of the group members of different ages who follow the same film, the common harmony and personal agreement, the group cohesion and the personal disagreement that the group must adhere to the group decision despite the opposition in the film. Sometimes the individual wants to use a technological tool to communicate with the group, but the majority opinion of the group may not be in this direction. Finally, both the majority opinion of the 
group and the individual may be in the direction of not using the technological tool (Allen \& Newtson, 1968). The epistemological hypothesis is based on the assumption that the knowledge and experience gained during this interaction will contribute to the interaction of the individual with intergenerational communication and technology.

\section{Social Impact}

The fact that majority decisions are stronger than minorities is made by social influence. Individuals want to get the approval of the majority, involve the social class, and maintain their position within the group and society. This situation requires to bear the burden of certain social influences brought about by inclusion. This is also important for intergenerational communication and interaction. The joint efforts of individuals who represent different generations, the use of technology takes place under social influence. Depending on the use of differences of technological products, the manner of use may be the result of this social impact (Gerard \& Miller, 1975).

\section{Normative Social Impact}

Good communication requires a harmonious and conflict-free process. Positive expectation of the individual in terms of harmony with other individuals forms the basis of normative social effect. It can be explained by the social influence that it is in accordance with the rules of the included group, that the group is self-accepting, that it is compatible with the members of this group to be able to enter a group to be included. It is expected that an elderly individual who wants to be involved in a group consisting of individuals with different demographic characteristics using new technological products will show an increase in the interest of technological relevance (Gerard \& Miller, 1975).

\section{Informational Social Impact}

Intergenerational communication involves the flow of information between individuals. The informal social influence explains the influence of information that individuals acquire from each other (Deutsch \& Gerard, 
1955). The attractiveness of individuals who start collecting around a seller who carries out a presentation of technological product points to a personal social influence. For, the fact that the people gathered around the seller has gained experience before, will apply in the next gathering. However, it should be acknowledged that normative social influence is more effective than informational social influence. Because the influence of the group or social effect on the individual is greater than individually acquired knowledge and experience (Baumeister \& Bushman, 2017). Informational social impact has significant effects on an individual's interaction with technology. The social impact can contribute to the interaction with technology by positively increasing the youth-elderly relationship.

\section{Informational General View Influence}

Groups formed by individuals often suddenly occur. Complex and abrupt groups are gathered around the same purpose. The cohort of these temporary groups acts to benefit. Individuals feel that some information and communities they have learned in advance will benefit. Thus, when individuals compare with a phenomenon that points to every general/total view, the tendency to this phenomenon increases. There are many reasons for the increased tendency. As well as providing the material benefit of acting in accordance with the common sense of the individual group, the inclusion of the group may also provide moral benefit to preserve the status of other groups or to participate in other groups. Because when it is acted with the total view, it is observed that other individuals are behaving in harmony with the group as well as normative social influence. This information, obtained through observation, has a positive impact on the individual who is observed to adapt at a later stage (Baumeister \& Bushman, 2017).

\section{Progressive Informational Social Influence}

Knowledge which is the source of informational social impact is not always acquired or transmitted at the same time and in the same place. Different individuals can reflect total view by exhibiting the same type of behavior at different times and different locations. On the two-way road, while there is 
no reason for the opposite vehicles to be found in the warning with their long headlights, learning to be a police turnaround in the forward part of the road, on the next trip you can be provided with the task of lowering the speed in the case of arousal by means of a headlamp or warning the other drivers not to catch a radar when you see a police officer (figure 1). This is clear evidence that collective behaviors of informational social influence may not occur at the same time and place (figure 1). The fact that the stimuli that occur at different times constitute a total view in the individual indicates that the informational social effect can be gradual. The stage is concerned with the ability to divide the information gained into time and place. Under the informational general view influence, the community can take place at different times. However, the interest of the individual only occurs when this total takes place.

The warnings of one individual may not affect the judgment of another. However, the influences on the individuals of the actions taken as a community are higher than individual ones. The communication of stimuli in progressive informational social influence can be differentiated in terms of time and space (Deutsch \& Gerard, 1955). The elderly individual's prejudiced approach to smartphone use can change when group members who are included see them at different times using the phone. In particular, an individual who has difficulty in using the technological device may change his / her thoughts by means of information obtained at different times from other individuals using the device (figure 2).

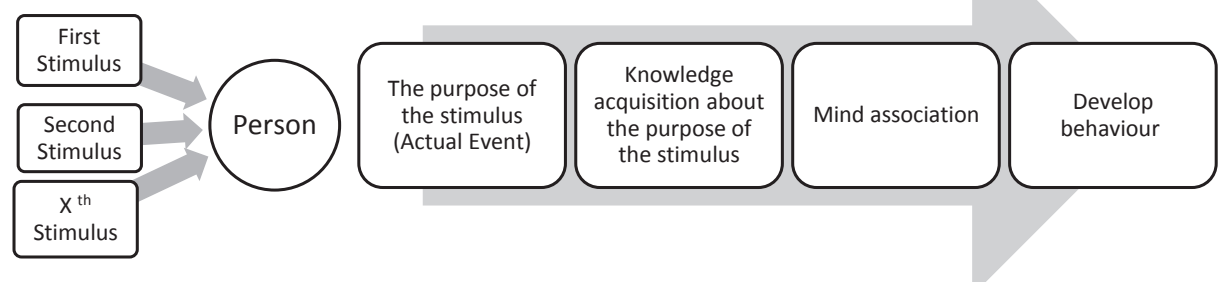

Figure 1. Progressive Informational Social Influence Period: First Case Source: Adapted from Hoffman \& Bateson (2016). 


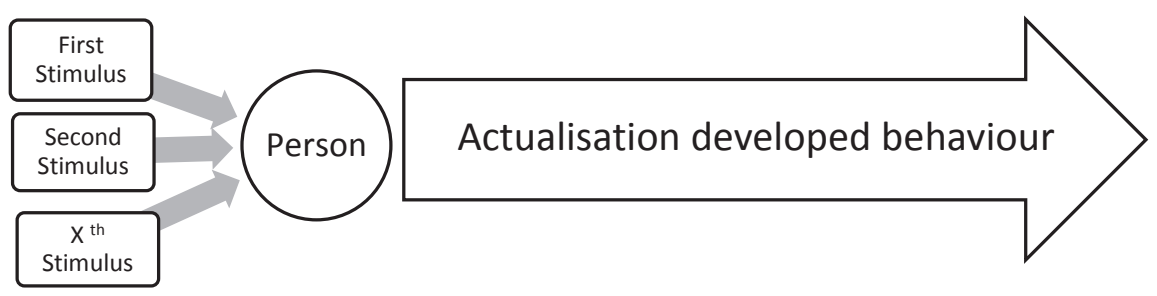

Figure 2. Progressive Informational Social Influence Period: Second Case Source: Adapted from Hoffman \& Bateson (2016).

Individuals can learn the intentions of stimuli after they have been exposed to the stimuli of different individuals of the same species at different times and places. The stimuli for which they are learned are associated with the person's mind. A behavior is developed that is associated with the stimulus and the result. This behavior is repeated if the stimuli of the same type are repeated. As long as the same type of outcome continues to be encountered as a result of the same type of stimulus, the interest shown to the increased number of stimuli may remain the same. As an example; the same behavior can be displayed when the number of stimuli after the second repetition of the event is two (regardless of the fifth stimulus) if the police control is encountered as a result of the warning of the first, second, third, fourth and fifth vehicles coming from the opposite side. The fact that the number of stimuli can cause the same effect on a person when the informational social effect is attributed to repeated events. The individual may limit the stimuli to at least two people when he or she meets the same result several times, and may not be adhered to a stimulus. Because there is always the possibility of error. However, this can vary from person to person. A more cautious individual can also apply the number of stimuli from previous experiences in subsequent events. The individual may develop or apply his / her developed behavior in a second or other events. For this reason, it is not possible to limit the number of events and stimuli (Glasser \& Salmon, 1995).

\section{Global Class Theory}

Global class theory is inspired by the past habits and experiences of each individual in society, the changing and evolving world needs, the generally 
accepted human-focused views. A lifestyle with a decent peaceful, economical and spiritual quality of life, legal, individual and political sense of security, a healthy living environment with a wide range of consumption possibilities are important targets in the generally accepted public life standards (Diener, 1984). These are the aims that the states and organizations want to provide to their members and in this sense they are involved in the necessary initiatives. Movements related to these goals begin with the individuals who form the core of the organizations. Individuals are as rational as emotional as they are idealistic. Individuals are sometimes elaborate, sometimes generic. Every individual is an active consumer. Individuals constantly consume their biological, physical, spiritual, material possibilities (Schifman, Hansen \& Kanuk, 2008). For this reason, individuals are active in consuming entities in an abundance of need. Individuals conflict with social and existential classes. Every human being is in conflict with other classes in his or her class, as well as the classes of animals and plants, as far as members of the class conflict. In the event of a conflict of individual interests, they generally exhibit selfish behavior. Because individuals prioritize the interests of their own, their family, or the social class to which they are subject. The individual may also exhibit an altruism attitude, which is a beneficial act for someone else if he knows that he will incur a burden (Campbell, 2006). Selfish or selfish behavior can reveal ethnocentrism among social classes. Although cultural self-reliance may support social stability, it may also hamper their understanding of their culture. Because when a group compares its traditions and folkway with those belonging to another group of cultures, its definition of superiority leads to prejudices and prevents cultural rapprochement. However, it should not be forgotten that no culture is superior to the other. Each culture has the qualities to make it valuable in itself. In the same way, social classes need to be evaluated in this context. Social classes also have a fragile structure that can not remove selfishness. Because the formation and continuation of each of the social classes depends on the total will of the individual. Every social class has a breaking point. The more people-focused the overall goals of the social classes are, the stronger the foundations will be. The social class distinctions that are being tried to be done with religious, ethnic, economic, managerial divisions have begun to leave to the human-oriented organizational social 
classes, which today also have their place in economic terms. The European Union, an interstate multinational organization, is an example of an effort to model an organizational social class. The European Union, with its slogan "In varietate concordia", is an important structure affecting social classifications (Simons, 2011). European Union; human orientation has created a model of superiors and transnational models by going to a structure where selfishness is the forerunner of economic rather than selfishness. The fact that the source of class struggles can be solved by social unification is beginning to form a common belief in individuals, validates global class theories.

Global classes consist mainly of educational, cultural, professional, and organizational classes. The classes created by individuals in the same education status constitute the class of education level. Groups of graduate and undergraduate graduates can be given as examples of graduates from business schools. Students may also be involved in this class. The class of individuals with the same cultural characteristics is the cultural class (Campbell, 2015). The cultural class is a very large social mass. The professional class is the class of those who are in the same profession or proficiency group. Professional classes such as engineers, lawyers, and other groups of professionals are examples. The occupational class does not consist solely of professional distinctions. Unemployed persons and employees are also included in the occupational class. Those who carry out professions that require proficiency or skill or other competencies are also included in the professional class to do business in a defined profession. The organizational class is the social class in which organizational structures such as non-governmental organizations, associations, foundations, serving the public institutions and organizations, companies that serve under a common purpose (Townsend \& Troung, 2017).

A class model of the core human is given in Figure 3. Headings were selected and categorized as much as possible in a general framework. Especially when the present industry, technology, information and communication elements are taken into consideration, it is possible to see the classifications within the above global cluster. There is no precedence relationship between classes. Classes have a transitional nature. The individual involved in a class may be included in the other class. For this reason, the transition will become more apparent as the 
classes are attempted to be privatized or separated into subgroups. Especially the social media class is growing in the face of the rapid progress of technology and communication. Growth is achieved by the formation of subgroups. The addition of a new social media tool multiplies or divides groups. The addition of innovations to social media tools like Facebook, Twitter, Tango, LinkedIn, Google Plus and Yahoo Groups are gradually expanding the social media category (Arfaa \& Wang, 2014). This affects older individuals as well, increasing intergenerational interaction. Elderly individuals can make friends by participating in social groups, communicate with individuals in the social environment and organize activities, especially through the internet. Thus, interaction with technology increases and intergenerational communication can be strengthened.

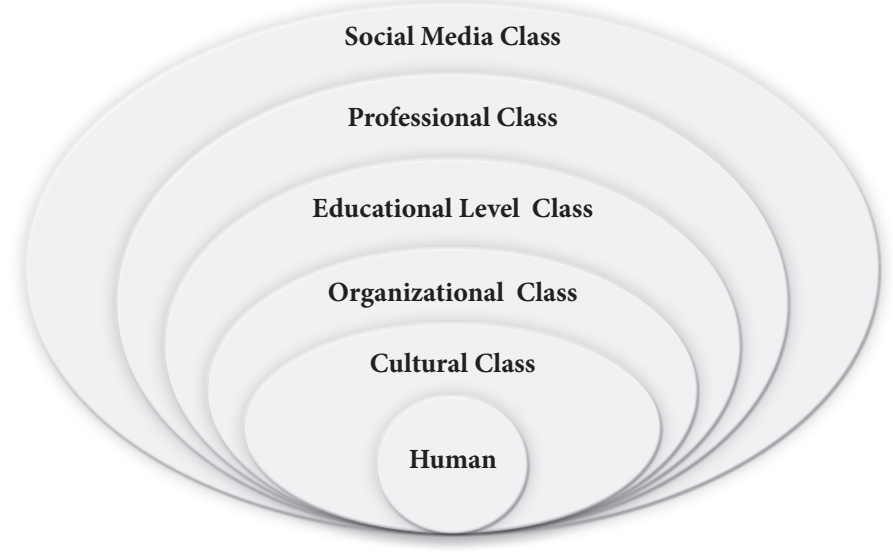

Figure 3. Global Class Globular Cluster

Source: Adapted from Argyle (1994).

The most important feature of the global cluster of global classes is the human being in the core. Thinking of social classes on a human basis provides the basis for intergenerational communication and elderly-group interaction. The downsizing, growth, association, division of one or more of the classes depends on the core. In brief, these classes are found and shaped by the core. The physical environment, geographical conditions also influence the class. However, classes do not only depend on geographical conditions. Against the effects created by physical and external influences, the sum of reflection movements that people create can lead to classes. For this reason, while it is 
possible to say that geographical factors have an impact on culture and social classes, it is not possible to say that these factors constitute a social class alone (Kraus, Piff \& Keltner, 2009).

\section{Technological Impacts on Elderly}

Innovations that digital innovations provide to today's world continue to reflect on every aspect of our life (Kaspar, 2004). The use of communication technology, which is included in the elderly and young population, continues to attract increasing attention. The acceptance of communication technology has begun to be investigated because the functions of mobile phones have increased with the developing technology and the necessity of communication which is indispensable to life. The increasing number of elderly population makes it necessary for the elderly to research the acceptance of communication technologies so that their needs can be met with communication technology. In this context, Chen and Chan (2014) 1012 elderly (256 males, 756 females) were interviewed about Chinese adults aged 55 years and older living in Hong Kong with 10 basic questions about gerontechnology acceptance, health, and ability characteristics, demographic characteristics, 5- point Likert scale, personal attitudes, age, and gerontechnology self-efficacy was found to be strong indicators.

The elderly themselves have the competence and needs associated with exclusive technology. Obstacles such as visual weakness, cognitive deficiencies, and usage problems are often observed among the elderly. Innovative technology has been identified by Kaspar (2004) as the low perception level of those who are interested. Russell, Peplau \& Ferguson (1978) found that mobile phone use was not related to loneliness, that there was a positive relationship between internet use and loneliness, that women used computers more for documentation, and men used computers to generate more web pages. In addition to factors such as the number of social relations, social environment, and education, technological products have been shown to reduce loneliness (Berg, Kemperman \& Kleijn, 2016). The need to reduce the feeling of loneliness nowadays leads individuals to use the internet and technological devices. According to this research, individuals who are not alone perform activities 
such as magazine reading and e-mail from the internet. Lonely individuals are interested in internet games.

Besides loneliness, information and social support are also important for the elderly individual. A study conducted by video conferencing showed that the individual reduced his loneliness but did not have any effect on social support. (Tsai et al., 2010). Adoption of technology by elderly people besides social support is important for successful aging, quality of life, motivation for loneliness. Wang, Rau \& Salvendy (2011) who surveyed older people about the adoption of information technology, found that: the elderly people are the four key factors influencing the acceptance of information technology, satisfaction needs, presence of support, perceived usability, social acceptance. Satisfaction and the presence of support are very important compared to perceived usefulness and social acceptance factors for the elderly. According to the results of the researchers' analysis, the satisfaction needs and the perceived usefulness are significantly related to the intention to use information technologies. Heart \& Kalderon (2013) found a significant relationship between perceived behavioral control and behavioral intentions in a survey of information and communication technologies on health over 63 years old in the USA and 60 years old in Israel. Besides, acceptance and use of technology contributes to the successful aging of the elderly person by providing active participation in the behavior (Rowe \& Kahn, 1997).

According to a study conducted by Kalınkara and Sar1 (2019), older individuals (60-64 years) used social networks for cooperation, their needs to communicate as their income increases, the means to reach the social network affected attitudes, and individuals who did not participate in social organizations were less likely to use social networking. Kalınkara, Başıüyük and Ay (2016), determined that elderly people used mobile phones, electric cooking tools, and remote-controlled vehicles, while they used electronic blood pressure devices, debit cards and credit cards less. According to another study, elderly people who were not users of computers approach the computer negatively and could not adapt (Kalınkara \& Sarı, 2018). 


\section{Ageism}

Discrimination is to see the gray color, not the shadow itself, but the negative aspects of the differences. Disparities and differences can be manifested in many ways, including gender, religion, culture, race, color, and intergeneration (Solem, 2016). This distinction between groups of elderly and young individuals has an important role in intergenerational communication. Intergenerational ageism is the prejudiced approach of one age group to the other, and this approach reflects on feelings, behaviors, and beliefs. The use of technology as a communication tool should not be designed to cause age discrimination among individuals involved in different age groups. In today's world, where the Internet is becoming widespread, time-work (debt payments, bank transactions, etc.) and shopping can be done virtually, technology is strengthening communication between older and younger individuals. The development of technology provides continuity of social networks and gradually reduces the inability to carry out daily activities due to physical insufficiencies. The elderly person who has to leave the home and wait for the bank transaction before the development of the internet and technology can now easily carry out the banking transactions through his computer or smartphone from home. Elderly individuals who can meet their daily food or clothing needs through virtual shopping can socialize with their loved ones through social media accounts and become acquainted with new people (Siegel \& Dorner, 2017). The elderly individual who follows the current news from the internet can follow the proceedings opened by the Ministry of Justice's National Judicial Network Project, write a petition with the e-signature without going to the courthouse, send it online to the court, to complain to the prosecutor's office online and be able to sue online. Thus, technology has overcome physical inadequacies that may lead to discrimination (Siegel \& Dorner, 2017).

\section{Conclusions and Recommendations}

The world population is getting older and the increase in the elderly population increases the importance of intergenerational communication. With the development of technology and the internet, social formations are 
increasingly differentiating and the interaction of individuals with technology becomes more complex. As individuals interact with social groups, the intention to use technology increases. This interaction is important in the context of relationships between social groups. The Global Class theory, which is one of the research topics of the study, is based on the view that unlike other classes, the integration of classes on a human basis. The Global Class approach, which may be a new movement of thought against the discriminatory approach of social classes in the literature, will play an important role in increasing the social interaction of elderly individuals.

Elderly individuals move away from social groups due to advancing age-related decline and the level of active participation in life decreases. To eliminate this decline, the participation of the elderly in the groups and social interaction should be increased. This interaction depends on the human-based social class approach. The importance of human factors should be considered in technology usage behavior. The impact of cultural, organizational, educational, professional and social media classes on the interaction between individuals is important in global class theory. These classes are those that develop on a human basis. This feature ensures that human values are not forgotten for the interaction of individuals in classes. Intergenerational interaction of elderly individuals is important in this context. Intergenerational communication is important for older individuals to adapt to technology and to interact with new technologies. The global class theory has a structure that integrates this communication and interaction based on human factors. Thus, exposing to ageism and social isolation are prevented.

The strength of this study is the fact that technology usage of the elderly is examined together with intergenerational communication, intergroup interaction and the newly introduced global class theory. Another strength of the study is the use of technology in elderly individuals with a new theoretical approach in the literature. On the other hand, the lack of empirical findings of the study constitutes the limitation of the study.

Increasing intergenerational communication and appropriate use of technology to educate conscious individuals may become more possible through formal and informal education. Awareness can be created in terms of 
intergenerational communication by emphasizing the ability of technology to communicate and interact with visual, printed, social and virtual media.

The elderly population and, concordantly, intergenerational interactions are increasing. The active involvement of universities, public education centers, non-governmental organizations, government incentives, and voluntary individuals, and the relationship between older and younger individuals can be improved through technology. Ensuring that in-service training is provided for the effective and efficient use of technology in terms of generations of communication in the organizations in which they work, and the organization of unintentional training, such as panels or meetings, for other individuals, will enable this to be recognized. The importance of communication in the use of technology in training and activities to be organized should be emphasized. It is also proposed to conduct qualitative and quantitative researches on acceptance and use of technology behaviors of elderly people in terms of intergenerational communication and social impact for future studies. 


\section{References}

Allen, V. L., \& Newtson, D. L. (1968). Conformity, Anticonformity, and Independence. Technical Report, No. 88, 21pp., Madison: University of Wisconsin.

Arfaa, J., \& Wang, Y. K. (2014). An Accessibility Evaluation of Social Media Websites for Elder Adults. In G. Meiselwitz (Ed.), Social Computing and Social Media, 6 th International Conference, SCSM 2014, Held as Part of HCI International, Heraklion, Crete, Greece, June 22-27, Proceedings (pp. 13- 24). London: Routledge.

Argyle, M. (1994). The Psychology of Social Class. London: Routledge.

Asch, S. E. (1951). Effects of group pressure upon the modification and distortion of judgment. In H. Guetzkow (Ed.), Groups, Leadership and Men (pp. 177-190). Pittsburg: Carnegie Press.

Baumeister, R. F., \& Bushman, B. (2017). Social Psychology and Human Nature, Brief Version. USA: Cengage Learning.

Becerikli, S. Y. (2013). Kuşaklararası İletişim Açısından Yeni İletişim Teknolojilerinin Kullanımı: İleri Yaş Grubu Üzerine Bir Değerlendirme. İstanbul Üniversitesi İletişim Fakültesi Dergisi| Istanbul University Faculty Of Communication Journal, (44), 19-31.

Berg, P. v. d., Kemperman A., Kleijn, B. d., \& Borgers, A. (2016). Ageing and loneliness: The role of mobility and the built environment. Travel Behaviour and Society, 5, 48-55.

Campbell, A. V. (2006). The ethical challenges of biobanks: Safeguarding altruism and trust.

Campbell, C. (2015). Making the middle class: schooling and social class formation. History of Education Review, 44 (1), 54-70. doi: 10.1108/HER-02-2014-0007.

Chen, Ke, \& Chan, A. H. S. (2014). Gerontechnology acceptance by elderly Hong Kong Chinese: a senior technology acceptance model (STAM). Ergonomics, 57 (5), 635652. doi: 10.1080/00140139.2014.895855

Chua, P.-H., Jung, Y., Lwin, M. O., \& Theng, Y.-L. (2013). Let's play together: Effects of video-game play on intergenerational perceptions among youth and elderly participants. Computers in Human Behavior, 29 (6), 2303-2311.

Deutsch, M., \& Gerard, H. B. (1955). A Study of Normative and İnformational Social Influences upon Individual Judgment. The Journal of Abnormal and Social Psychology, $51(3), 629-636$. 
Diener, E. (1984). Subjective Well-Being. Psychological Bulletin. 95, 542-575.

Egolf, D. B. (2001). Forming Storming Norming Performing: Successful Communications in Groups and Teams. Lincoln, NE: Writers Club Press.

Festinger, L. (1950). Theory and Experiment in Social Communication. Ann Arbor, MI Research Center for Dynamics, Institute for Social Research, University of Michigan.

Gass, R. H., \& Seiter, J. S. (2014). Persuasion: Social Influence and Compliance Gaining. Routledge.

Gerard, H., \& Miller, N. (1975). School Desegregation. Springer Science \& Business Media.

Giles, H., Coupland, N., \& Coupland, J. (1991). Accommodation theory: Communication, context, and consequence. In H. Giles, J. Coupland, \& N. Coupland (Eds.), Contexts of accommodation: Developments in applied sociolinguistics (pp. 1-68). New York: Cambridge University Press.

Glasser, T. L., \& Salmon, C. T. (1995). Public Opinion and the Communication of Consent. Guilford Press.

Gumperz, J. J. (1992). Contextualization and understanding. In A. D. \& C. Goodwin (Eds.), Rethinking context: Language as an interactive phenomenon (pp. 229-252). New York: Cambridge University Press.

Gumperz, J.J., Aulakh, G., \& Kaltman, H. (1982). Thematic structure and progression in discourse. In J. J. Gumperz (Ed.,) Language and social identity (pp. 22-56). New York: Cambridge University Press.

Hammerl, M., Dorner, F., Foscht, T., \& Brandstätter, M. (2016). Attribution of symbolic brand meaning: the interplay of consumers, brands and reference groups. Journal of Consumer Marketing, 33 (1), 32-40. doi: 10.1108/ JCM-12-2014-1243.

Harwood, J., \& Giles, H. (2005). Intergroup Communication: Multiple Perspectives. NY: Peter Lang Publishing Inc.

Heart, T., \& Kalderon, E. (2013). Older adults: Are they ready to adopt health-related ICT? International Journal of Medical Informatics. 82 (11), 209-231. doi:10.1016/j. ijmedinf.2011.03.002.

Heider, F. (2012). The Psychology of Interpersonal Relations. Psychology Press.

Hjälm, A. (2012). Because we know our limits: Elderly parents' views on intergenerational proximity and intimacy. Journal of Aging Studies, 26, 296-308. 
Hoffman, K. D., \& Bateson, J. E. G. (2016). Services Marketing: Concepts, Strategies, \& Cases, 5th Ed., Cengage Learning.

Hummert, M. L. (2010). Age group identities, stereotypes, and communication. In H. Giles, A. Reid, \& J. Harwood (Eds.), The dynamics of intergroup communication (pp. 42-52). Lang, New York.

Kalınkara, V., Başıbüyük, G. Ö., \& AY, F. (2016). Yaşlıların Geronteknolojik Ürünleri

Kabule Yönelik Tutumları. Yaşlı Sorunları Araştırma Dergisi, 9(2), 1-19.

Kalınkara, V., \& Sarı, İ. (2018). Yaşlıların Bilgi Teknolojileri Kullanımı Ve Yaşam Doyumu:

Potansiyel Ve Engeller, Ergonomik Yaklaşım. Mühendislik Bilimleri ve Tasarım Dergisi, 6(1), 1-13.

Kalınkara, V., \& Sarı, İ. (2019). Yaşlılarda Sosyal Ağ Kullanımı ve Yalnızlık İlişkisinin

Belirlenmesi. Yaşlı Sorunları Araştırma Dergisi (YSAD), 12(1), 8-19.

Kaspar, R. (2004). Technology and Loneliness in Old Age. Gerontechnology, 3 (1), 42-48.

Kraus MW, Piff PK, \& Keltner D. (2009). Social class, the sense of control, and social explanation. Journal of Personality and Social Psychology, 97, 992-1004.

Kruglanski, A. W., \& Stroebe, W. (2011). Handbook of The History of Social Psychology. Psychology Press.

Lamb, C., Hair, J. \& Mcdaniel, C. (2009). Essentials of Marketing. Mason, OH: SouthWestern Cengage Learning.

Lantos, G. P. (2011). Consumer Behavior in Action: Real- Life Applications for Marketing Managers. M. E. Sharpe.

Levine, J. M. (2013). Group Processes. Psychology Press.

Olson, K.E., O’Brien, M.A., Rogers, W.A., \& Charness, N. (2011). Diffusion of Technology: Frequency of Use for Younger and Older Adults. Ageing International, 36 (1), $123-$ 145.

Paulus, P. B. (1989). Psychology of Group Influence, 2nd Ed. Psychology Press.

Petticrew, M., \& Roberts, H. (2008). Systematic reviews in the social sciences: A practical guide. John Wiley \& Sons. 
Rabbie, J. M. (1982). The effects of intergroup competition and cooperation on intragroup and intergroup relationships. In V. J. Derlega \& J. Grzelak (Eds.), Cooperation and helping behavior: Theories and research (pp. 123-149). New York: Academic Press.

Radford, K. J. (1989). Individual and Small Group Decisions. New York: Springer Science, Business Media LLC.

Rosengren, K. E. (2000). Communication: An Introduction. Sage Publications, London.

Rowe, J. W., \& Kahn, R. L. (1997). Successful Aging. The Gerontologist, 37 (4), 433-440.

Russell, D., Peplau, L. A., \& Ferguson, M. L. (1978). Developing a measure of loneliness. Journal of personality assessment, 42(3), 290-294.

Ryan, E.B., Meredith, S.D., MacLean, M.J., \& Orange, J.B. (1995). Changing the way we talk with elders: Promoting health using the Communication Enhancement Model. International Journal of Aging and Human Development, 41, 89-107.

Schiffman, L. G., Kanuk, L. L., \& Hansen, H. V. (2008). Consumer attitude formation and change. Consumer Behavior: A European Outlook, 247-80.

Schulz, H. M. (2015). Reference group influence in consumer role rehearsal narratives. Qualitative Market Research: An International Journal, 18 (2), 210-229. doi: 10.1108/ QMR-02-Stutgart 2012-0009.

Siegel, C., \& Dorner, T. E. (2017). Information technologies for active and assisted livingInfluences to the quality of life of an ageing society. International Journal of Medical Informatics, 100, 32-45.

Simons, G. F. (2011). Euro Diversity. Routledge Taylor \& Francis.

Solem, P. E. (2016). Ageism and age discrimination in working life. Nordic Psychology, 68 (3), 160-175. doi: 10.1080/19012276.2015.1095650.

Strydom, J. (2004). Introduction to Marketing. Juta And Co Ltd.

Tajfel, H., Turner, J. C. (1985). The social identity theory of intergroup behavior. In S. Worchel \& W. G. Austin (Eds.), Psychology of intergroup relations (2nd ed., pp. 7-24). Chicago: Nelson- Hall.

Townsend, S. S. M., \& Troung, M. (2017). Cultural models of self and social class disparities at organizational gateways and pathways. Current Opinion in Psychology, 18, 93-98 
Tsai, H-H, Tsai, Y-F, Wang, H-H, Chang, Y-C, \& Chu, H. H. (2010) Videoconference program enhances social support, loneliness, and depressive status of elderly nursing home residents. Aging \& Mental Health, 14 (8), 947-954. doi: 10.1080/13607863.2010.501057.

Uman, L. S., Chambers, C. T., McGrath, P. J., \& Kisely, S. (2008). A systematic review of randomized controlled trials examining psychological interventions for needle-related procedural pain and distress in children and adolescents: An abbreviated Cochrane review. Journal of pediatric psychology, 33(8), 842-854.

Uman L. S. (2011). Systematic reviews and meta-analyses. Journal of the Canadian Academy

of Child and Adolescent Psychiatry = Journal de l'Academie canadienne de psychiatrie de l'enfant et de l'adolescent, 20(1), 57-59.

Wang, L., Rau, P-L. P., \& Salvendy, G. (2011). Older Adults' Acceptance of Information Technology. Educational Gerontology. 37 (12), 1081-1099. doi: 10.1080/03601277.2010.500588.

Wang, H.H., Wu, S.Z., \& Liu, Y.Y. (2003). Association between social support and health outcomes: A metaanalysis. Kaohsiung Journal of Medical Sciences, 19, 345-351. 